\title{
Constructing the Personal Narratives of Lesbian, Gay and Bisexual Asylum Claimants
}

Laurie Berg and Jenni Millbank

Faculty of Law, University of Technology Sydney

PO BOX 123, Broadway NSW 2007 Australia

Correspondence to: laurie.berg@uts.edu.au and jenni.millbank@uts.edu.au

This is a preprint of an article which will appear in published

form in (2009) 22 (1) Journal of Refugee studies

Abstract

This article draws upon psychological and sociological literature to explore the issues that arise in eliciting and presenting a refugee narrative when the claim is based upon sexual orientation. Rigid notions of homosexual identity may consciously or subconsciously shape decision-makers' approaches in this field. First, we identify psycho-social issues of particular significance to lesbian, gay and bisexual claimants which may act as barriers to eliciting their narrative of self-identity, including: a reluctance to reveal group membership as the basis of a claim, the experience of passing or concealment strategies, the impact of shame and depression on memory, common experience of sexual assault, and sexualisation of the identity narrative in the legal process. Secondly, we explore factors which inhibit the reception of such narratives in the legal process. In particular we explore the psychological 'stage model' of sexual identity development and examine the pervasive impact this model has had upon decisionmakers' 'pre-understanding' of sexual identity development as a uniform and linear trajectory.

Keywords: refugee narratives; sexual orientation; lesbian, gay, bisexual refugees; sexual identity; particular social group.

\section{INTRODUCTION}

Over the past 15 years many thousands of refugee claims based upon sexual orientation have been made under the Refugees Convention. Despite initial doubt over whether sexual orientation could be regarded as a particular social group for the purposes of the Convention, by the mid to late 1990s this was well accepted in most refugee receiving nations (Dauvergne and Millbank 2003, 97, although note there is continued divergence in the approach of the various circuits of the federal appellate courts in the United States: see O'Dwyer 2008). Subsequently, the major focus of contest in sexuality based claims was the interpretation of persecution, in particular whether criminal sanctions for homosexual sex are persecutory and whether claimants could or should be expected to conceal their identity in 
order to avoid persecution (Millbank 2005). These questions of law have gradually become more settled (UNHCR 2008, paras 17-22, 12-13, 25-26) although still contested in some jurisdictions, in particular the United Kingdom (UK) (Millbank 2009a). Issues of factual assessment, which have always been significant, now appear to be rising in prominence. Decision-makers in countries such as Australia and Canada appear increasingly likely to disbelieve that the applicant is actually gay, lesbian or bisexual on the basis that her or his claimed identity is not 'plausible' (Millbank 2009b).

This article draws upon psychological and sociological literature to explore the particular issues that arise in eliciting and presenting a refugee narrative when the claim is based upon sexual orientation. These issues are illustrated with reference to case examples from all of the available tribunal and court decisions from Canada, Australia, the UK and New Zealand (see Appendix for details and limitations of this case set). While drawing on a large case set covering a 15 year period, we have deliberately focused upon decisions issued in more recent years in order to provide the most current picture possible.

A narrative of sexual identity must be presented as comprehensively as possible early in the process because the requirement of consistency of later testimony is such a significant feature of refugee adjudication, leading to an undue focus on the 'first' account and concurrent neglect of any original content presented at oral hearing (Amnesty 2004, 20; Byrne 2008, 627; Kneebone 1998, 82; Coffey 2003, 388-9). While many claims to refugee status rest largely, or entirely, upon the personal narrative of the applicant, this is more likely in claims which are based upon sexual orientation. Refugee claims based upon political opinion, nationality, race or religion will more commonly have some form of independent verification of group membership, whereas a claim to belong to a particular social group on the basis of sexual orientation depends upon the presentation of a very internal form of self identity. We found a common refrain in case law that 'allegations' of gay identity are easy to make and hard to disprove (Millbank 2009b). Furthermore, while claimants on all grounds often face the difficulty of speaking about experiences of torture and trauma, including sexual assault, in recounting past persecution, sexual orientation claims are unique in the sense that extremely private experiences infuse all aspects of the claim. Feelings of shame and self-repression in revealing the kind of information necessary to make a claim of group membership manifest distinctively in sexual orientation claims, even though similar difficulties may arise in detailing persecution on other grounds (LaViolette 2004, 5).

How the asylum claim is articulated depends on the relational interaction between advocate or decisionmaker and asylum seeker at every stage of the process; it is a story told and received in highly mediated ways. Marita Eastmond has observed that we need to be mindful to distinguish between, 
life as lived, the flow of events that touch on a person's life; life as experienced, how the person perceives and ascribes meaning to what happens, drawing on previous experience and cultural repertoires; and life as told, how experience is framed and articulated in a particular context and to a particular audience. Past experience is always remembered and interpreted in the light of the present as well as by the way that the future is imagined. What is remembered and told is also situational, shaped not least through the contingencies of the encounter between narrator and listener and the power relationship between them. (Eastmond 2007, 249, emphasis in original).

The immediate context of personal disclosure for claimants during the asylum process is shaped by the legal requirement of proving a well-founded fear. British researchers have observed that, in this way, the 'emotional condition is at the heart of the legal definition' (Herlihy and Turner 2007a, 268). Yet Gregor Noll argues that the power dynamics of refugee determination procedures dictate that the construction of the applicant's life story cannot challenge foundational tenets of the decision-maker's understanding of the world (Noll 2006, 499). The refugee is most likely to be seen when she or he looks like 'us' or, when that is not possible, looks like what is being looked for (Millbank 2002, 155ff). As we explain below, what is being looked for is heavily influenced by Western conceptions of the linear formation and ultimate fixity of sexual identity. At the same time, there seems to be little awareness of the psychological issues faced by lesbian, gay or bisexual individuals which can impact upon how such identities are negotiated in the asylum interview, and how any narrative of self-identity is framed in the initial application.

In the first section of this article we outline some of the barriers to eliciting an applicant's narrative of self-identity. In the second part we address barriers to the presentation and reception of such narratives in the legal process. In particular we explore the psychological 'stage model' of sexual identity development and examine the pervasive impact it has had upon decision-makers' 'pre-understanding' of sexual identity development as a uniform and linear trajectory.

\section{ELICITING AN IDENTITY NARRATIVE}

In refugee claims concerning sexual orientation independent verification of group membership is often unavailable, and may be given little weight even when present. Few claimants are able to present a partner from a current same-sex relationship. Advocates may therefore seek to prove the claimant's sexuality through introducing documentary evidence such as photographs of lovers, membership of lesbian and gay community groups, or through testimony by friends or professional counsellors. 
Paradoxically, while decision-makers preferred 'objective' verification, our research also found documentary evidence frequently disregarded as self-serving or staged (eg Australia N05/50659 [2005]; Canada Yakovenko [2004]). Likewise counsellors' opinions on sexual identity were vulnerable to dismissal as simply a retelling of the applicant's own narrative (eg Canada T99-06929 [2000]; see also Herlihy, Gleeson, Turner 2009). Thus, overwhelmingly, it was the applicant's own testimony of her or his self-identity that founded the claim.

The context of asylum claims means that every claim is expressed amidst some degree of emotional distress; claimants may have suffered physical and/or sexual violence, witnessed traumatic incidents, experienced the violent loss of loved ones or conducted much of their lives in secret under threat of persecution. Psychological issues of particular significance to lesbian, gay and bisexual claimants include: a reluctance to reveal group membership as the basis of a claim, the experience of passing or concealment strategies, the impact of shame and depression on memory, common experience of sexual assault, and sexualisation of the identity narrative in the legal process.

Reluctance to Reveal Group Membership

Prevailing societal homophobia provokes feelings of shame and the consciousness of being the subject of disapproval or disgrace. Feelings of internalised shame may be particularly strong in lesbians and gay men because their experiences of discrimination and stigmatisation have persisted without the coping mechanisms available to other minorities. Unlike other traditionally oppressed groups, sexual orientation is not necessarily a visible characteristic; it has to be revealed and is likely to be experienced for some time in isolation and secrecy. A recent psychological study found that one in four Asian selfidentified gay or bisexual men in China, Korea, Japan and the US had not told even one friend about their sexual orientation (Kimmel and Yi 2004, 164). In particularly repressive societies disclosing one's sexual orientation may simply be too threatening, such that many lesbians and gay men suppress their identities, dealing with their emotional reactions to their sexual orientation without any assistance (Chung and Katayama 1998, 23). It may not be possible to identify others with similar experiences because lesbian and gay communities are invisible in the country of origin or because fear of repercussions prevents emerging lesbians or gay men from seeking them out (Meyer 1995, 41; Flowers and Buston 2001, 52).

Claimants may therefore have talked to only a handful of people, or none at all, about their sexual orientation prior to making a refugee claim. The dynamics of the interview with the claimant and their 
perception of the decision-maker, advocate or translator will significantly affect whether the claimant feels sufficiently comfortable and safe to disclose her or his identity. A sense that the interviewer is not receptive to, or is sceptical about, the applicant's homosexuality will also weigh in the applicant's risk assessment as to the prudence of revealing their sexuality. Further, the claimant's willingness to disclose may also be affected by the sexual, gender or cultural identity of the questioner. Psychological researchers have found gay men of minority cultures often experience a tension between these two aspects of their identities (Bhugra 1997, 556) and may therefore be more reluctant to come out in a setting which includes someone from the same culture. We found that decision-makers often failed to notice or consider the impact of a same-culture or opposite-sex translator on the ability of a claimant in sexual orientation matters to tell their story (Millbank 2009a; see also LaViolette 2004, 6). The onus to identify and raise such issues therefore rests heavily upon advisors.

Lesbian and gay applicants from countries in which homophobia is state sanctioned or encouraged may find it hard to imagine that state officials could be anything other than hostile to discussion of homosexuality. They are also more likely than claimants on other grounds to be unaware that their group membership is a recognised basis for a refugee claim in the receiving nation (LaViolette 2004, 6). Our review of decided cases found that delay in making a refugee claim, or in articulating sexuality as the basis for a claim, was relatively commonplace (Millbank 2009b). Advisers should therefore not be surprised if sexual orientation is first mentioned by the applicant relatively late in the process, and may indeed be prefaced by a false, or weak, claim on another ground.

\section{Concealment and Avoidance Strategies}

Because gay men and lesbians are exposed to a range of negative stereotypes long before they realise their own sexual orientation, the internalisation of these negative images complicates the development of a self-assured, integrated gay or lesbian identity. Pervasive effects from such internalised shame have been found even in a group of highly educated, occupationally successful, predominantly White lesbians in the United States (Wells and Hansen 2003, 104). As a result, lesbians, bisexuals and gay men may adopt strategies to evade or manage the stigma of being labelled as homosexual which involve selectively disowning their sexual orientation to themselves and to others (Troiden 1989).

Thus, applicants may display vestiges of past or current denial about their homosexual feelings, extreme ambivalence about their sexuality, or use terminology that is redolent of homophobia. When applicants referred to their homosexuality in the course of the hearing as a 'problem' or an 'addiction' we found 
that this was often taken as evidence that they were not actually gay, for example in an Australian decision from 2001:

he said he did not mention this fact because both the interviewer and interpreter for his entry interview were women and that he therefore could not talk about his 'problem' with them. By 'problem' he indicated that he meant 'sexual problem', the term he used to describe homosexuality throughout his statement. Whilst claiming to view expression of homosexuality as a right, the Applicant thus also depicted it as a kind of deficiency or defect...

The Applicant only ever referred to his claimed sexuality as a sexual or psychological problem. He showed no sign in his evidence of ever having seen his sexuality as a matter of private right. (N01/37891 [2001], 9, 20. See also Australia N05/51729 [2005] and, in contrast, NZ Refugee Appeal No 73252/02 [2002] para 8).

Such ambivalence may reflect internalised homophobia, may simply reflect the only language that the applicant has been accustomed to hearing and using concerning sexuality, or it may bear a negative connotation by virtue of the words chosen by a translator. ${ }^{1}$

Many applicants may have spent long periods of time 'passing' as heterosexual, pretending in one or more contexts to be straight in order to safely avoid a potentially threatening situation, to avoid confronting friends or family with their homosexuality or to themselves avoid dealing with difficult or unwanted feelings. Yet, we found that decision-makers frequently drew adverse inferences on credibility when asylum seekers had adopted such strategies which were seen as 'inconsistent' with a claimed lesbian or gay identity (Millbank 2009b, an approach cautioned against by UNHCR 2008, paras 13, 36). In a 2006 decision the Canadian tribunal held that a claimant from Nigeria could not be gay because he had married and it was 'highly improbable' that a homosexual would father two sons in such circumstances. While the Federal Court overturned this decision, holding that the tribunal had erred in ignoring the wealth of evidence on the need to live a double life in Nigeria (Leke v Canada [2007]) there appears to be less understanding of self-denial or passing strategies if undertaken in the receiving country. In the 2004 Canadian case of Khrystych the applicant had a brief relationship with a woman after arriving in Canada.

The claimant was asked to explain why he carried on this relationship with Inna given his homosexual tendencies. In his written narrative, he explained that he wanted to be her friend, he appreciated their relationship and admired her. In testimony, he explained that he wanted to find a proper place in his life and to try and change himself. (Para 6, emphasis added).

The tribunal held that this was not a reasonable explanation and 'did not have a ring of truth' (quoted at para 6) . 
Advisors may counter such scepticism by eliciting from the asylum applicant an account of her or his use of such passing or avoiding strategies and the reasons for them, such as the experience of negative attitudes towards their sexuality. Further, as we note below, the development of sexual identity is not universal or linear. Nor does it hold true that a claimant reaches some higher state of self-actualisation, coinciding neatly with her entry into the receiving country or her articulation of her claim for refugee status. Expert evidence by psychologists may be helpful in explaining to an adjudicator how 'repressive social norms and negative experiences' may impede the acceptance of homosexual identities, as well as the common occurrence of a mixed sexual history through such process (see eg NZ Re ED [1996], 7).

Trauma, Shame, Depression and Memory

An applicant may be unable to talk about an experience, or they may actually be unable to remember it. Dissociation regularly manifests as a protective mechanism in high-stress settings, and the refugee status determination environment is an obvious trigger (Bögner, Herlihy and Brewin 2007, 80; Herlihy and Turner 2007a, 269). Depression and post-traumatic stress disorder (PTSD) have been shown to be associated with a pattern of overly generic memory, in which individuals have difficulty retrieving memories of specific events, including but not exclusively traumatic memories (Herlihy and Turner $2007 \mathrm{~b}, 3)$. Clinical research on the recall of refugees in Britain has demonstrated that high posttraumatic stress and the length of time between interviews significantly raised discrepancy rates in autobiographical narratives (Herlihy, Scragg and Turner 2002, 326). In addition to their response to trauma and persecution, claimants on the basis of sexual orientation may experience depression as a result of grappling with the development of their sexual identity, which may still be in a state of flux or uncertainty at the time of the claim.

A number of recent empirical studies have explored the impact of shame and trauma on the disclosure of personal information in the refugee process. In a London study of refugees with a history of premigration trauma, those with a history of sexual violence reported greater overall severity of PTSD and avoidance symptoms, greater feelings of shame and greater difficulty in disclosure of personal information during their initial refugee interview (Bögner, Herlihy and Brewin 2007, 78). Three-quarters of respondents reported that the first time they talked about the traumatic event was after their arrival in the UK, and for a majority this was during the refugee intake process itself. Many participants reported feeling too traumatised, afraid or ashamed to speak at all or to tell all details in these early stages, and noted that there were things that they had not revealed because in their culture it was 
considered wrong to discuss them. Such considerations are also highly relevant in claims involving sexual orientation.

\section{Sexual Assault}

UNHCR Guidelines on Gender-Related Persecution note that sexual orientation and gender claims are linked in that non-conformity to socially or culturally defined gender roles is a key aspect of both (UNHCR 2002, para 16). For this reason, we suggest, sexual assault is likely to be a common feature of both kinds of claim (Millbank 2002, 161; LaViolette 2007, 187). Our research found high levels of reported sexual assault in refugee claims based upon sexual orientation. In our study we found that in the Canadian decisions the reported rate of sexual assault was 45 per cent for lesbians and 24 per cent in claims by gay men. In Australian decisions 37 per cent of decisions concerning lesbians and 7 per cent of those concerning gay men contained a report of sexual assault, while in UK decisions 28 per cent of decisions involving lesbian claimants and only 2 per cent of gay male claimants reported sexual assault. While the reported rate was highest in all claims in Canada and lowest in the UK it is notable that for women it varied little between the three countries, while the difference for men was dramatically marked - from 24 per cent in Canada down to 2 per cent in the UK. Claims involving both women and men who have experienced sexual assault could be assisted through the use of gender guidelines originally developed to recognise the experiences of women.

UNHCR gender guidelines state that 'it is unnecessary to establish the precise details of the act of rape or sexual assault itself' (UNHCR 2002, para 36, xi). UNHCR also recommends that claimants 'should be informed of the choice to have interviewers and interpreters of the same sex as themselves' (UNHCR 2002, para 36, iii). Canadian gender guidelines direct attention to the need for sensitivity and training for those receiving testimony from women who have experienced sexual assault (Immigration and Refugee Board 1996, para D3). Yet national and international gender guidelines appear to have been completely ignored at tribunal level in Australia and the UK in cases concerning both gay men and lesbians (Millbank 2009a). In Canada gender guidelines have been very little utilised in claims by lesbians ${ }^{2}$ and almost completely overlooked in claims by gay men (LaViolette 2007, 199). Nicole LaViolette notes that the Canadian tribunal

usually accommodates requests from counsel that hearings be conducted with all-female personnel when it is believed that this will allow a woman to present her claim more fully. But when male victims of sexual abuse began requesting that female personnel be appointed to the hearing, the Board struggled with how to respond. $(2007,199)$. 
Particularly disturbing is the 2003 Canadian case of Mahmood, in which a 25 year old man claimed his first male-male sexual experience when he was 15 involved being sexually assaulted by two older boys. The male tribunal member repeatedly questioned the applicant about details of this experience and disbelieved him because he did not spontaneously report pain or bleeding and because 'this core evidence was not offered in a straightforward manner' (para 21).

When the claimant was asked what the boys did to him, he responded, they raped me. He was asked what kind of sex did they perform with you to which he responded simply they had sex with me.

Even when asked by his counsel physically what did they do with you, the claimant stated they bent him over and told him not to say anything. When I asked if the boys subjected him to anal sex, he responded, they had.

I am satisfied, on a balance of probabilities, that if such a rape occurred...the claimant as a 25 year old who now has had multiple gay sex partners, would have recounted details of his first sexual experience, in a more straight-forward manner than what occurred at his hearing. (Paras 22-24).

Here, familiarity with consensual adult male-male sex is taken to mean that the claimant will have no difficulty in recounting in detail an early experience of male-male rape. This is a completely unreasonable assumption.

Gender guidelines are also relevant to the substantive interpretation of sexual assault as an act of persecution. In the 2003 Canadian case of Re BYU, the tribunal accepted that the applicant was sexually assaulted by a group of four police officers, and that this had been reported to police by staff at the hospital where he received treatment. Yet the tribunal held that the applicant had not displaced the presumption of state protection because he himself had not gone to the police. It is particularly disturbing that this was upheld by the Federal Court on the basis that it was 'reasonable to expect' the applicant to pursue the police failure to act (Mora [2004] para 9). This finding flies in the face of the Canadian gender guidelines which instruct that when considering whether the claimant ought to have sought state protection, decision-makers should be aware of the specific impact of sexual assault on the ability to seek help, as well as the possibility that sexual violence at the hands of state actors will increase the difficulty of substantiating a claim (Immigration and Refugee Board 1996, para C2).

Yet despite the two extremely negative examples explored above, it is plausible that the dramatically higher rate of sexual assault for gay men in the Canada cases compared to Australia and the UK 
represents a higher rate of reportage rather actually reflecting a difference in occurrence. If so, then this may be suggestive of greater overall sensitivity to issues of sexual violence in the Canadian process.

\section{Sexualisation of the Narrative}

It is not uncommon for tribunal members to question applicants about consensual sexual experiences, in order to test the veracity of the applicant's narrative of sexual identity (Millbank 2009b). In such instances decision-makers may expect that applicants can both vividly recollect, and clearly articulate, their first sexual experiences in order to demonstrate that they are indeed gay or lesbian. Both of these assumptions are extremely problematic.

Firstly, the individual's state of mind during such experiences may well have been one of inner turmoil, confusion or dissociation. Particularly if a great deal of time has passed, and/or if the experience was followed by negative repercussions, initial confusion may be compounded by a process of habitual internal denial with many conscious and unconscious attempts to forget the experience. Even embedded sensory memory may not be specific as to date; a vividly recalled experience, for example, may be recalled only as something that occurred in winter, or on a cold day, rather than on a particular date, or on a Monday. Yet in the 2003 Canadian case of Charles (overturned on judicial review in 2004) the tribunal member disbelieved the applicant because he could not name the exact date, only the month, of his first sexual experience.

Secondly, it is also important to note that any questioning about personal milestones, such as 'first attraction', assumes that questioner and respondent have comparable conceptualisations of sexual attraction which may not be borne out (Diamond and Savin-Williams 2000, 306). Such mismatch may be further exacerbated by the translation of what appear to be simple terms from one language to another. It is apparent from case reports that a question such as 'when did you first know (or become aware) that you were gay/lesbian?' can be understood variously by the interlocutor and the applicant to mean first feeling of same-sex sexual attraction, first sexual encounter, first sexual relationship or first conscious acknowledgement of any of the above to either oneself or to another person. In a 2004 Australian case the applicant gave different ages in response to questions about when he 'realised' or 'became aware' that he was gay. From a close reading of the decision it appears that these two answers may have referred to different life events: one referred to the age at which the applicant felt a same-sex attraction while the earlier age was when he realised that he was not attracted to girls, yet his credibility was impugned by reason of this inconsistency (N04/49655 [2004], 4. See also Kagan on his experience of the 
culturally relative conception of the word 'knew' in the refugee context: 2003, 393). Interviewers may shy away from clarification of exactly what is meant through embarrassment, yet inconsistent answers arising from such lack of clarity can be devastating to an applicant's case.

Finally, it should not be expected that relating detail of an intimate sexual relationship will be anything other than a fraught, embarrassing experience for any person. Such difficulties are exacerbated when the experiences are of same-sex attraction. The process may also be transformed from generally mortifying to particularly discriminatory if the form of questioning is intrusive or use of terminology inappropriate (for example in one Australian case, a witness giving evidence that he believed the applicant to be gay was suddenly asked by the tribunal, 'When did you have sex with him last?' and in the same hearing the applicant himself was asked 'Did you adopt a male or female role in those relationships?': quoted on re-hearing RRT Reference 060403696 [2006]). We found sexually specific questioning of applicants in the hearing process was commonplace and that hesitation, vagueness and lack of a 'free-flowing' response were often taken as adverse to applicants' credibility in such circumstances (Millbank 2009b). For example, in 2006 the Federal Court of Canada found that it was open to the Board to draw a negative inference from the Applicant's inability to clearly describe his sexual activities with his alleged lover in Georgia' (Magradze [2006] para 6, emphasis added). Particularly troubling is the 2004 Canadian case of Kravchenko in which a 45 year old male claimant from the Ukraine was found to be 'vague and hesitant in his testimony with respect to his experiences as a homosexual person' (para 8):

The claimant was asked to describe how he and Vladimir became lovers. He testified by mutual consent. The claimant was asked again. He hesitated, saying that it was an intimate thing. The claimant based his claim on being a homosexual man. He was represented by counsel and knew that the onus was on him to establish his claim, but was vague in describing how the relationship was established. The claimant alleged that he was invited to Vladimir's place for tea, that he was the only one who went there and went about once a week.

The claimant was asked how Vladimir let him know he was interested in the claimant. The claimant alleged that they had preliminary conversations, that it was not premeditated, was impromptu and that they became lovers. The member declared specialized knowledge, indicating that she was aware that at this period in Ukraine's history, homosexuality was a crime. Given this, the claimant was asked how the relationship went from an invitation to tea to becoming lovers. The claimant alleged that they established a kinship, began with caresses and then the act itself took place. The claimant was asked how Vladimir knew that the claimant would be receptive to his advances. The claimant again hesitated and alleged that it was souls gravitating to each other. When asked how Vladimir knew he could take that risk, the claimant stated that he was not 
prepared to answer such a question. When asked what Vladimir said to him with respect to his interest in him sexually, the claimant responded that that is how it happened. ...

The claimant could not explain how the intimate relationship started and refused to explain how Vladimir, a sergeant, would take the risk of communicating his interest in the claimant as a lover. ... On a balance of probabilities, I find that the claimant had difficulty in describing elements of the alleged relationship with Vladimir because no such relationship existed. (Kravchenko [2004] paras 10-12. The decision was overturned on judicial review, for other reasons discussed below: Kravchenko [2005]).

This kind of questioning would surely be confronting even for people who were secure in their sexuality and well accepted by peers and family. It is also hard to conjecture in this case how one could satisfy the tribunal regarding a 'plausible' mode of communication of sexual attraction taking place in the context of a persecutory cultural environment. For this reason, we concur with LaViolette $(2004,12)$ and UNHCR (2008, para 36) that although inquiries into areas that touch on the claimant's personal experience as a gay man or lesbian will provide a solid basis for establishing that he or she is a member of the particular social group, such inquiries should not address sexual acts.

\section{PRESENTING AN IDENTITY NARRATIVE}

In training materials developed for the Canadian refugee tribunal, LaViolette suggests that one may build a narrative of sexuality that is not about sexual activity through questions that explore, for instance, when the claimant came to realise their sexual orientation, what kinds of discrimination and repression were prevalent in their home society, details about any past or current relationships, whether the claimant has disclosed their sexual orientation to their family and friends and what difficulties they might have faced in doing so, and whether the claimant has spent time with other lesbians or gay men in their country of origin or country of asylum (2004). Given the great diversity of human experience and understanding of sexual identity both within and across genders, cultures and other divides, there are few even broadly common aspects in the experience of same-sex attraction. LaViolette's structured approach to eliciting a narrative of self-identity is helpful in that it focuses on perhaps the one universal in the experiences of lesbian and gay men around the world other than the actual experience of homosexual sex: the hegemonic nature of heterosexuality which forces one to develop a sense of lesbian or gay identity in opposition to this norm (Morris 1997, 4). The development 
of a sense of self that reflects same-sex attraction is one of difference, triggering a process of identity (trans)formation/redefinition accompanied by the experience (or fear) of social rejection.

However, dangers can also attend a list of topics such as these in exploring identity if they become calcified in an interrogation style which assumes that there is a typical evolution of self-identity. We are concerned that this has in fact occurred in decision-making forums in Canada, Australia and the UK. Western understandings of minority sexual identity development have been deeply influenced by the idea of a linear process of self-knowledge moving from denial or confusion to 'coming out' as a selfactualised lesbian or gay man. This pervasive meta-narrative of homosexual identity was born in the psychological and sociological disciplines in the 1970s and now permeates popular culture (Liang 1997, 288). So ubiquitous has the 'coming out story' become that open-ended questions about a claimant's sense of their homosexuality such as those proposed by LaViolette may be co-opted by pre-existing cultural expectations that sexual development conforms to a linear trajectory. Below we explore the origins and development of the idea of a linear 'coming out' trajectory, how it has played out in the adjudication of refugee claims, and why it is important for refugee advocates and advisers to understand and problematise such an approach.

The Staged Model of Identity Development

In 1979, Australian psychologist Vivienne Cass proposed a staged model of homosexual identity formation (Cass 1979; 1984). This model theorises that identity develops through a series of discrete stages: Identity Confusion, Identity Comparison, Identity Tolerance, Identity Acceptance, Identity Pride and Identity Synthesis. According to this theory, the individual initially recognises some homosexual feelings or thoughts which lead him to inwardly question his own, and others', presumptions that he is heterosexual. Such internal confusion may initially lead to denial of homosexual impulses and selfloathing (Burke 1997, 84; Cox and Gallois 1996, 4). With a growing sense of a homosexual self-identity, the individual begins to experiment in same-sex encounters and may make contact with homosexual communities. Negative connotations of minority sexual identities may bring the individual pain and a sense of isolation and he is likely to prefer to remain hidden, 'passing' within the predominantly straight society. Only later does the individual reach a greater level of acceptance of his sexual orientation, selectively disclosing it to others and increasing contact with other homosexuals. Finally, the individual may achieve pride in, and a growing synthesis of, their identity with more positive self-regard, a deeper understanding of homosexuality as one integrated facet of the self and renewed congruity between the public and private selves. Over time, this psychological theory of sexual identity development has 
infused popular consciousness, shaping our cultural expectations of the 'natural' progression of sexual identity formation or standard 'coming out story' (Herman 2005; Millbank 2004, 166; Robson 1998, 87111).

Critiques of the staged theory of sexual identity development include that it is based upon a specific cultural and gendered experience of sexuality that may not be more broadly applicable and that even within such caveats it cannot adequately account for the diversity of human experience of sexuality. These criticisms, and the role that the expectation of a linear staged experience of coming out has played in the decision-making process, are explored below. We note that the stage model may be all too readily collapsed into an assumption that the 'final' stage of identity synthesis will occur in conjunction with the adjudication process.

\section{Cultural Blindness}

It is important to note at the outset that staged models of sexual identity development were derived from a Western experience and perspective, which may not be applicable to other cultural contexts. The majority of research on gay identity development has been conducted on White middle-class men in the United States with little consideration of non-Western expressions of minority sexualities (Rowen and Malcolm 2002, 78; Gençőz and Yúksel 2006) especially among women (for exceptions see Blackwood and Wieringa 1999; Blackwood 2000; Whitam et al. 1998). Expecting the sexual identities of people who live or grew up in non-Western countries to comply with a stage model overlooks the extent to which culture and social context powerfully contribute to self-perception and behaviour (Vance 1989). Even within the United States, researchers suggest that men from ethnic minority communities differ from both White male populations, and from one another, in the timing and sequence of milestones in the coming out process (see eg Dubé and Savin-Williams 1999; Wong and Tang 2004, 155).

In our examination of refugee status determinations, we found numerous instances of decision-makers drawing conclusions about the claimants' sexuality based on over-generalisations, such as that it is 'typical' for lesbians and gay men to become aware of their sexual orientation in adolescence (see eg Canadian tribunal cases, reviewed and disapproved on this basis in Eringo [2006] para 11; Dosmakova [2007]). Such an assumption, however incomplete a representation of Western experience, may be yet more misleading when applied to other cultural contexts. Unfortunately, when cultural relativity of sexual identity was acknowledged in the decision-making process this was often done in such a way as to deprive the applicant of the power to categorise their own experiences. For example, in some 
cultures male-male sexual activity is not uncommon in early life due to heightened proscriptions on premarital heterosexual sex, leading to a clear disjuncture between cultural meanings attached to same-sex activity and same-sex attracted identity. Applicants claiming to be homosexual whose only same-sex sexual experiences were early in life (and especially those who had later heterosexual experiences) were thus readily characterised by decision-makers as having a 'youthful transient phase' or 'sexual play' regardless of their claimed self-identity (eg Australia N05/50659 [2005], 18; UK EK (Uganda) [2004] para 16).

\section{Sexuality as Fixed and Discoverable}

In the refugee context, it is always the decision-maker and not the applicant who has the power to name, the authority to decide who the applicant 'really' is and what sexuality 'really' means (McGhee 2000, 34. See eg Australia SZEHT [2005] para 5). This is exemplified in the following exchange, drawn from transcript of a hearing in Australia in early 2003, quoted on judicial review:

[Tribunal]. Right, so when do you say that you first become involved in homosexual activity in Sydney?

[Applicant]. Last year, a year ago. That's when there was actual contact. I did have friendships before that but I didn't - I didn't sort of decide on any further steps at that time.

[Tribunal]. The note that I've made is that your first actual homosexual activity in Sydney was roughly in September 2001.

[Applicant]. All right.

[Tribunal]. Is that reasonably accurate?

[Applicant]. Mmm.

[Tribunal]. All right. Now - - -

[Applicant]. It was winter, yeah, around September.

[Tribunal]. The other thing that I noticed particularly in your statement was that you said, 'I am still confused about my sexual identity.' That suggests to me that you are not a person who has finally made up your mind that you are a homosexual.

[Applicant]. Well, it is written like that because I have had sex with a woman as well and I cannot say that I'm a homosexual if I have sex with a woman - that's in Ukraine. 
[Tribunal]. Yes, I saw that.

[Applicant]. I know - I know what it is and I can compare it.

[Tribunal]. And I saw that severally.

[Applicant]. What is severally?

[Tribunal]. Well, I saw where you said that you had had some relationships with women in Ukraine before coming to Australia but I wonder if pressing that you would care to explain to me what confuses you at the present time about your sexual identity.

[Applicant]. Well, I haven't had too many contacts - had too many relationships, I've had only two partners. I cannot say, for instance, that I've been heterosexual until 24 years of age and then suddenly became homosexual, I can't say that, that's why but now I'm with men only. This girl who is my witness, I mean, we lived in the same place for four months but we had no relationship and she was offended by that.

[Tribunal]. But you've now told me that you regard yourself as being exclusively homosexual. Why say only a week or so ago that you're still confused about your sexual identity?

[Applicant]. Well, I don't know, because I had sex with women. I thought that it would be incorrect to write anything else.

[Later in the hearing].

[Tribunal]. I suppose my other difficulty is that accepting that you are a practising Roman Catholic, how you reconcile your Roman Catholic faith with your homosexual practices in Sydney - - -

[Applicant]. Well, I never thought about that.

[Tribunal]. - - - because I certainly accept that you're a Roman Catholic.

[Applicant]. I never thought about that. (Quoted on review SZAKD [2004] para 8). ${ }^{3}$

The tribunal went on to find that:

At hearing the applicant admitted to still being confused about his sexual identity. Although the applicant sought to explain this statement it causes me to have serious doubts that the applicant is a homosexual. Further at the hearing when asked how as a practicing [sic] Roman Catholic he reconciled his homosexuality with the Catholic faith his response was that he had never considered the matter. This response, together with his confusion with respect to his homosexuality is sufficient to satisfy me that the Applicant's claims of being homosexual are not genuine. Having regard to the current teachings of the Catholic Church, I am firmly of the view that a person of single sex orientation must have at least considered their position in the Church and whether they wished to continue practise (sic) Catholicism. ... I am not satisfied that the claims of the Applicant that he is a homosexual are genuine. (Para 8). 
This questioning and decision betrays a clear expectation that sexual identity must be experienced and articulated within certain parameters in order to be plausible. Here, a homosexual may have had early heterosexual relations, but these must be disclaimed in the process of adopting an exclusive, unambivalent homosexual identity which is then named as such (see also Rehaag 2008 on the frequent use of 'confused' as a descriptor of bisexual claimants in Canada). A homosexual identity also requires the conscious examination (and rejection?) of any other societal frame, such as religious affiliation, with which it may come into conflict. Notably this latter approach has been rejected at judicial level in both Canada and Australia as relying upon improper stereotyping (Canada Trembliuk [2003] para 5; Australia SZAKD [2004]).

Staged theories, like the model proposed by Cass, organise major milestone events in a linear sequential progression for developing a clear sense of oneself as homosexual in a heterosexual world. While this may well accurately reflect the experiences of some, it can lead to the misapprehension that there is a single path to one 'real' sexual identity, from the same starting point. The model suggests that everyone moves through generally similar stages, in the same order and without revisiting a previous stage (Johns and Probst 2004, 82). It also assumes that the whole drive of the process is for the individual to come to accept his or her one, 'real' sexual identity which is then acknowledged to the world at large. This reflects an essentialist view that sexual orientation is either innate or established early in life (Troiden 1989) and defines what one 'really is', a view that sits readily with legal approaches that seek to categorise distinct, knowable groups such as those under the Refugees Convention (LaViolette 1997, 30$31)$.

Yet we contend that much psychological and sociological literature demonstrates that rather than forming a unitary 'core' of a person's conception of self, sexuality is not absolute and can take on varying meanings as a dimension of a person's life. So for example, homosexuality may be the basis for social (or group-based) identity for some people and personal identity (based on desire and behaviour with no sense of broader social association) for others. Yet we found that some decision-makers expected that members of sexual minorities would, as a matter of course, form a sense of group identity and either join or demonstrate knowledge of lesbian or gay groups. For example in the 2004 Canadian case of Laszlo the applicant had not known of an organisation in Romania called 'Accept' and this was held to impugn his credibility because,

[i]t would seem reasonable to expect that the existence of an organization that is supportive of lesbian and gay rights would not go unnoticed by a gay person, especially if the panel is to believe the claimant that homosexuals in his country were mistreated and marginalized. (Para 6). 
This finding was upheld on judicial review as a 'logical plausibility finding' (Laszlo [2005] para 10. But see contra Charles [2004] para 10). We contend that such approach improperly collapses the personal and political aspects of individual identity and places an unduly high burden on claimants to establish social manifestations of what may be experienced by them as private sexual desires or beliefs. Requiring such outwardly visible dimensions of sexual orientation is especially problematic in a persecutory environment.

Further, personal and social identities can be contradictory such that people self-categorise as a heterosexual (in terms of their group association) but seek out sexual behaviour with people of the same sex (Cox and Gallois 1996, 15). Equally, some people can arrive at a social homosexual identity without having ever engaged in homosexual behaviour. The staged model may preclude awareness of such possibilities by positing homosexual behaviour as a prerequisite to identity integration (Horowitz and Newcomb 2001, 15-16). This was borne out in our study as decision-makers were demonstrably reluctant to accept claimants who could not establish prior same-sex relationships (eg Canada KRU [2002]; Australia N04/49292 [2004], an approach expressly rejected by UNHCR 2008, para 38). For example in a 2006 Canadian case the tribunal held that the applicant's account of his feelings for other young men and solitary use of gay pornography in the absence of homosexual experience when he had been 'in constant contact with boys' at school had 'not established his identity as a homosexual man' (TA5-13949 [2006], 4, 3). Conversely, homosexual behaviour without an articulated identity formation process may be rejected as inauthentic. In a 2006 case an applicant who had never had consensual gay sex in his home country of Pakistan, had a previous heterosexual relationship and then formed a longterm gay relationship while in immigration detention in Australia. The applicant claimed to be bisexual but his relationship, while accepted as truthful, was characterised by the tribunal as like many similar relationships formed between inmates in prisons ... simply the product of the situation where only partners of the same sex were available and said nothing about his sexual orientation' (RRT case 060635653, upheld on judicial review SZJSL [2007]).

Gender Blindness

Another significant flaw with the staged theory of identity development is that it was originally based upon male accounts. This model has since been taken as a generic account of homosexuality while excluding, or indeed misrepresenting, the experiences of lesbians (Morris 1997, 5; Gonsiorek and Rudolph 1991; Diamond and Savin-Williams 2000, 297). In fact there is considerable clinical evidence that same-sex attracted Western women and men have very different processes of identity formation, 
including typically different sequences of events. For example, it appears to be more common for men to experience gay sex before consciously identifying as gay as well as more common for them to have a first sexual encounter with a male with whom they are not otherwise intimate. In contrast, women tend to internally identify that they are lesbian or bisexual prior to having any sexual contact and such sexual contact usually takes place within an ongoing relationship of emotional intimacy (Diamond and SavinWilliams 2000, 308). The 2007 Canadian case of Dosmakova dramatically illustrates how a linear male model of identity development may impact especially adversely upon women:

The claimant was asked when she realized about her sexual orientation. She replied that it was only when her relationship with $\mathrm{N}$ began [when the claimant was 56]. While this is unusual, it is possible. But things must be probably so, not just possibly so. On a balance of probabilities, I find that most homosexual people have some realization with respect to their sexual orientation when they begin to explore their sexuality in their teens or early twenties, even if they suppress it, hide it, or fail to acknowledge it. On reflection in later life, they are cognizant of this perhaps latent sexual orientation. This was not the case with the claimant. She found out about her lesbian sexual orientation only when she began such a relationship. The claimant stated in her [application] that she was happy with her husband, although she was surrounded by women. While this is not determinative, it adds to the claimant's lack of credibility. (Quoted on judicial review Dosmakova [2007] para 11).

While the tribunal decision was overturned by the Federal Court which held that this conclusion was made on the basis of stereotype rather than evidence (as was the finding, discussed below, that the claimant could not be happy to make such a discovery about herself) it must be recalled that only a small fraction of refugee decisions ever go to review. In addition it is possible that there are many more first instance decisions where such views about the 'probable' path of sexual identity development are less overtly expressed.

Much research suggests that the expression of female sexuality is far more likely to be fluid than male sexuality. A recent study into the self-identity and sexual experience of 167 young women in the United States, which included not only self-identified lesbians but also women with any physical or romantic interest in women, found that

[c]ontrary to the notion that most sexual minorities undergo a one-time discovery of their true identities, $50 \%$ of the respondents had changed their identity label more than once since first relinquishing their heterosexual identity. (Diamond and Savin-Williams 2000, 301)

Diamond and Savin-Williams conclude that " $\mathrm{t}$ ] he notion of "true" sexual minorities presumes categories where there may be continua, and "coming out" presumes a single outcome where there may be 
several' $(2000,303)$. According to these researchers, 'variability in the emergence and expression of female same-sex desire during life course is normative rather than exceptional' $(2000,298)$.

It therefore appears not at all unlikely that lesbian refugee claimants will have had previous heterosexual relationships, have interspersed heterosexual and lesbian relationships, or have maintained a heterosexual marriage while in a serious lesbian relationship. Yet such variability of sexual expression - either as the result of an authentic variation in attractions over time or through co-option of preferred sexual expression by dominant cultural norms - is often taken to impugn credibility (Canada AA0-1226/27 [2001]). For example, in a 2006 Canadian case, an applicant from the Ukraine, claimed that

[s] he knew that she was a lesbian since she was a student at the technical school which she attended from 1974 to 1979. She tried to express her interest in a lesbian relationship in 1979 but her advances were rejected. She married to hide her situation and did not attempt a lesbian relationship until after her husband died, when in 1993 the claimant attempted another lesbian relationship but was again rejected. In 2002, the claimant met XXXXX and had a relationship with her which they hid for two years until the claimant's brother found them kissing. (TA5-12778 [2006], 1.)

The third relationship ended when the applicant's partner left her to move to England with a younger man. The tribunal rejected the account, finding that, '[w]hile it is not impossible for someone to be bisexual it is, on a balance of probabilities, not plausible for the claimant to make three unsuccessful relationships' $(5,6)$. The reference to bisexuality as 'not impossible' suggests that it is the fact that all three women remained with, or returned to, men which rendered this account implausible. Likewise in an Australian case in 2000 the tribunal held that it was 'somewhat implausible' for the lesbian applicant's partner to have had a 'heterosexual affair in the middle of a long-standing homosexual relationship' (N98/22328 [2000], 6).

We found that women were disproportionately over-represented in claims based on 'bisexuality' in both Canada and Australia. ${ }^{4}$ Although it is hard to generalise because of the small numbers of such claims, it appears that applicants who self-categorise as bisexual have a somewhat lower success rate than those identified as homosexual ${ }^{5}$ (see also Rehaag 2008). Bisexual claimants may be seen by decision-makers as more able to 'pass' and avoid persecution by virtue of a heterosexual relationship (NZ Refugee Appeal No 75376 [2006]). Bisexual applicants are also more vulnerable to poor credibility findings if they are in a heterosexual relationship at the time of the claim.

It may therefore be tempting for advocates to choose a term to categorise the applicant's sexuality which they feel will give the best chance of success: homosexual. Yet this may not be an accurate 
descriptor of the applicant's identity or of their behaviour and, importantly, any shift in category or terminology by the applicant during the process is likely to be taken as adverse to their credibility or as suggesting a lack of conviction in their identity (eg Australia N97/15882 [1997]). Claims for group membership on the basis of bisexuality are particularly challenging for advocates who must take care to fully explore the transition or fluidity in the claimant's sexual orientation and identity and yet at the same time contextualise such variability in terms of the claimant's experience of well-founded fear of persecution.

Progress and the Expectation of an 'End' Stage

The idea of a linear staged progress of identity development may be all too readily collapsed into a 'progress' meta-narrative in which the end point of self-actualisation is represented by entry (and assimilation) into the receiving country. In particular we found that decision-makers commonly assume that once the applicant has left an oppressive or persecutory environment their sexuality will be openly and easily expressed through same-sex relationships and/or an 'out' identity in the 'free' receiving country (eg Canada Akhtar [2004]; Hussain [2004]; Magradze [2006]). This is a very problematic assumption if the applicant has in fact continued to be closeted in the receiving country, has struggled to form relationships there or has oscillated in their self-identity through the process (see eg Canada Khrystych [2004]).

Conversely, the progress narrative assumes that there can be no joy or freedom in the experience of homosexuality in the country of origin, only fear. When applicants have stated that they were happy, content, or had no regrets about discovering their sexuality, decision-makers disbelieved them on the basis that the discovery could not be attended by such positive emotions in a persecutory environment (eg Canada Osayamwen [2004] para 10; GPC [2003] para 13). In the 2006 Canadian case of Dosmakova, discussed above, the tribunal stated:

The claimant testified that she and N were friends from 1994 and that in 2000 she and $\mathrm{N}$ became lovers and N. moved in with her to facilitate her trip to work. The claimant was asked how she felt about her discovery. She replied that she felt happiness and sexually satisfied, that she was happy about it and had no regrets. I do not accept this as credible. The claimant was a fifty-six-year-old woman, living in a society which she stated was homophobic. This departure from her previous life style was drastic. On a balance of probabilities, I find that the claimant, if she suddenly discovered that she was a lesbian in such circumstances, her emotional reaction was not in harmony with the preponderance of probabilities which a reasonable and informed person would expect. On a balance of probabilities, even if the claimant does not regret her relationship with $\mathrm{N}$, it is reasonable to expect that she would express some misgivings with respect to her initial 
feelings. Therefore, on a balance of probabilities, I find the claimant not to be a credible or a trustworthy witness. (Quoted on review: Dosmakova [2007] para 11).

There is also a prevalent assumption that, in addition to being wholly unwelcome, homosexuality is utterly involuntary. In the 2004 Canadian case of Kravchenko the applicant referred to his first same-sex relationship as 'a voluntary thing, he realized that was really his path' (para 8). When he referred to his sexuality as 'his choice' the tribunal asked the claimant:

to confirm that he made the choice to be gay and he did so. I do not accept this as reasonable. The claimant is a well-educated man who understood the consequences of being gay. It is unreasonable that such a man would choose a life style which would inevitably cause him problems ... Although not determinative, on a balance of probabilities, the claimant's description of his experience of his recognition of being a homosexual is inconsistent with someone who is truly gay. (Para 8).

Whether the applicant in this case was saying that he chose to act upon his feelings or that he in fact felt that he had a choice to be gay is actually unclear, but it is striking that the decision-maker could not countenance the idea that being 'truly gay' involves some measure of volition. This finding was held to be 'perverse and capricious' and reversed upon judicial review where it was characterised as reflecting, 'at best', 'an uninformed view of male homosexuality; at worst, ... reliance on preconceived ideas about homosexuality' (Kravchenko [2005] para 6).

The progress meta-narrative threatens to fundamentally distort reception of the individual claimant's story because it implicitly posits that the refugee adjudication will occur at the conclusion of the process. This assumes that the applicant, having earlier struggled with self-identity, has now come to terms with it and can (or in the refugee context, must) reflect back: they are now out and can tell their coming out story. This is problematic for a number of reasons. Firstly, this dovetails with a tendency within Western gay communities, psychological literature and broader society to assume that the ideal or healthy end state of this process is one of a full and final disclosure (Dindia 1998, 88). Yet coming 'out' is not a single definable moment but an activity that is continually repeated over time to a multitude of people in different contexts, with varying meaning and effect. Moreover, such an approach overlooks the many and varied reasons why lesbians and gay men choose to conceal or reveal their sexuality. As Gail Mason notes, 'the decision to come out to others frequently involves a careful (although sometimes spontaneous) weighing of the likely rewards and possible repercussions' (Mason 2002, 81). Mason argues that the 'closet',

proffers a strategic means of control over the extent to which one is subjected to the undesirable implications of being marked as gay or lesbian in everyday life, such as disparagement, 
discrimination and hostility... Once an individual makes a declaration of homosexuality there is no means to control or redress the ways in which that knowledge is interpreted by others $(2002,82)$.

In our view decision-makers often grappled unsuccessfully with the experience of applicants who regulated the bounds of their own out-ness or exercised 'information control' (McGhee 2000, 46), by for example being out to a circle of friends, but closeted with family and employers, or who on arriving in the receiving country were out to a counsellor or joined a lesbian and gay group, but remained resolutely closeted to friends or other members of the same ethnic community. So, for example, in a UK case in 2000 a man's claim to be at risk as openly gay if returned to Pakistan was rejected by an adjudicator on the basis that he was not really out: 'although he behaves socially as an open and admitted homosexual, he has not informed either colleagues at work or his family' (quoted and upheld on review in R v Special Immigration Adjudicator Ex Parte T [2000] para 11; see also para 47). In the 2002 Canadian case ZNB the applicant testified he was harassed by neighbours and others, yet his parents did not know that he was gay, a situation which the tribunal held was 'not plausible' (paras 2526). In these instances the expectation of out-ness as singular and universally known moment demonstrably worked to defeat the applicants' claims.

There is no reason to expect that most, or even many, applicants will be in the final stages of an identity synthesis process at the time they leave their country or when they make their way through the refugee determination procedures. In the Western tradition, the expectation of coherent narrative about life experience requires self-reflexivity. We expect a narrator to have objective distance about herself, to be able to describe different times in her life in relation to her self at present, such as, 'I was married to a man because I felt I had no choice at the time; I felt terribly ashamed of who I am at first, but I have been much happier since I came out as a lesbian last year'. The expectation of self-reflexivity deeply informs adjudication of the narrative (Eastmond 2007, 249), yet reflective distance may not be a fair or realistic tool to determine the narrative's truth or authenticity. One area where this has been most apparent has been the numerous cases in which applicants have been closeted in their country of origin and not faced acts of persecution in the past as a result. Recent law suggests that if secrecy or concealment of sexuality has been caused by fear of persecution then the experience of living in secrecy may itself be considered as a form of persecution (Australia Appellant S395/2002 [2003]). However, decision-makers continue to find that applicants are simply 'naturally' discreet or have lived their 'preferred lifestyle' of 'self imposed restraint' (NZ Refugee Appeal No 71355/99 [1999]) - meaning, in fact, absolute secrecy - such that fear of persecution is either not well-founded or not for reasons of group membership (Millbank 2009a). This kind of reasoning continues in part because claimants have 
not clearly presented a case articulating their mode of living as a conscious and coerced response to oppressive social forces or a lifestyle which may be subject to change over time or in a new social context: rather their life as lived is simply the way things are (see most recently in the UK: JM [2008]; HJ, Iran [2008]).

Finally, a staged approach may be mistakenly interpreted as representing a linear passage from a period of poor self-worth to one of psychological health, leading to an unrealistic expectation of the applicant's emotional state. In fact, Australian researchers who subscribe to the staged model found a significant decline in gay men's well-being and increased isolation, distress and depression during the middle stages of gay identity formation, while positive psycho-social indicators were higher during the initial identity confusion and the final identity synthesis stages (Halpin and Allen 2004, 117). Importantly, this is at odds with the lay assumption that well-being would start low and gradually and systematically increase as the individual becomes more and more accepting of his gay identity. Advocates and advisers should therefore be open to the prospect that applicants confronting the implications of their sexuality may well be experiencing their lowest emotional ebb at the time of making their claim, rather then enjoying new found 'freedom' in the receiving country.

\section{CONCLUSION}

There has been an increased tendency in recent years to disbelieve claims of group membership for lesbian, gay and bisexual refugee applicants (Millbank 2009a; 2009b). We are concerned that rigid notions of homosexual identity may consciously or subconsciously shape decision-makers' approaches to sexuality in asylum claims. A stage model, while offering some insights into the process of sexual identity development, may be both overly simplistic and misleadingly applied. Despite instruction by courts in countries such as Canada that decisions about sexual identity must not be based upon stereotype, the conception of sexual identity development as a universal form of linear 'progress' appears in numerous cases as a template against which the veracity of individual claims are judged.

A Guidance Note recently issued by the UNHCR recognises the importance of specialist training for government officials involved in all aspects of the interview process, whether as interviewers, decisionmakers or interpreters, and cautions that such training should engender not just a familiarity with issues faced by sexual minorities but also should encompass appropriate interview techniques (UNHCR 2008, para 37). We concur with the UNHCR that issues relating to sexual orientation must also be 
'mainstreamed' in the ongoing training of officials, especially regarding the proper bases for credibility assessments of claimants.

We argue that it additionally falls to refugee advisors and advocates to labour to overcome the stereotyped assumptions regarding sexuality and sexual identity development which so often underlie such determinations. The challenge is to elicit a nuanced narrative which explains apparent inconsistencies and complicates neat categorisations of human sexual experience, yet at the same time to present this narrative in such a way that it is recognisable to the decision-maker and meets the legal criteria necessary to establish group membership. We acknowledge that such tensions may never be entirely resolvable, and necessarily involve compromise. However, we contend that an approach which is open and sensitive to the complex psycho-dynamics of the client's development of self-identity and acts of coming out can assist in both eliciting and presenting narratives for refugee claimants on the basis of sexual orientation.

\section{Appendix}

This data set comprises over 1000 cases, being all of the publically available tribunal and court decisions involving a claim to refugee status based upon sexual orientation in the years 1994-2007 (inclusive) in Canada, Australia, the UK and New Zealand. Australian cases were all obtained from the Austlii case database (www.austlii.edu.au). UK cases were obtained from the Electronic Immigration Network case database (www.ein.org.uk), the Asylum and Immigration Tribunal website (www.ait.gov.uk) and LEXIS. Canadian cases were obtained from the Quicklaw, Canlii (www.canlii.org) and LEXIS databases. New Zealand cases were obtained from the Refugee Status Appeals Authority website (www.nzrefugeeappeals.govt.nz). There were a total of 528 Australian decisions made up of 369 decisions from the Refugee Review Tribunal (RRT) and 159 judicial review decisions from the Federal Court of Australia, Federal Magistrate's Court and Federal Court. There were 116 UK decisions made up of 70 tribunal decisions and 46 judicial review decisions from the Queen's Bench and Court of Appeal. There were 397 Canadian decisions, comprising 276 tribunal decisions and 121 judicial review cases drawn from the Federal Court of Canada and Federal Court of Appeal. There were 38 New Zealand cases made up entirely of tribunal decisions. The United States was excluded from the study due to the unavailability of lower level determinations.

In Australia, New Zealand and the UK the original decision on refugee status is taken by a delegate of the Minister, who is a bureaucratic officer. If this determination is negative, the applicant can apply for a de novo merits review of the decision. In Australia this review is undertaken by the Refugee Review Tribunal (RRT) which sits with a single member. In New Zealand this review is undertaken by the Refugee Status Appeals Authority (RSAA) which sits with two members. In the UK until April 2005 this review was undertaken by the Immigration Appellate Authority (IAA) in a two tier system: first, an 
immigration adjudicator reviewed the decision de novo and then leave could be given to the Immigration Appeal Tribunal (IAT) which until 2002 provided a second level of de novo review and after 2002 was limited to points of law by the Nationality, Immigration and Asylum Act 2002 (UK). From 2005 the two-tier structure was abolished and replaced by the Asylum and Immigration Tribunal (AIT): Asylum and Immigration (Treatment of Claimants, etc) Act 2004 (UK). The AIT can only grant review based on an error of law. Canada is unique in that the tribunal makes the first determination. Until 2002 this body was the Convention Refugee Determination Division which sat in two member panels, with a difference between the members resulting in a positive determination. Since 2002 the new Refugee Protection Division sits with only one member.

Note that although our set comprises all available decisions, not every decision made is released. For instance in Australia, while all RRT determinations were released prior to 1999, after that point the target for release was only 20 per cent of decided cases, and in recent years fewer than 10 per cent of decisions have been released. We estimate that the Canadian cases in our pool represent less than 5 per cent of actual determinations made on sexual orientation in that period in Canada (see discussion in Millbank 2009b).

\section{Acknowledgements:}

This research is part of a larger project examining gender and sexual orientation in refugee claims across the UK, Australia, New Zealand and Canada conducted with Catherine Dauvergne at the University of British Columbia and funded through an Australian Research Council Discovery Grant. Thanks to Anna Samson and the journal reviewers for their comments, and to Katherine Fallah and Marianna Leishman for their research assistance.

\section{Cases Cited:}

\section{Australia}

Appellant S395/2002 v Minister for Immigration and Multicultural Affairs (2003) 216 CLR 473.

N01/37891 [2001] RRTA 889 (16 October 2001).

N04/49655 [2004] RRTA 773 (6 December 2004).

N04/49292 [2004] RRTA 750 (26 November 2004).

N05/50659 [2005] RRTA 207 (17 May 2005).

N05/51729 [2005] RRTA 311 (8 November 2005).

N97/15882 [1997] RRTA 3396 (5 September 1997).

N98/22328 [2000] RRTA 542 (16 May 2000).

RRT Reference 060403696 (22 November 2006), decision is also not publicly available, accessed by the authors through a Freedom of Information request and on file with them. 
RRT Reference 060635653 (23 October 2006), decision not publically available, on file with authors.

SZAKD v Minister for Immigration and Multicultural and Indigenous Affairs [2004] FMCA 78 (19 March 2004).

SZEHT v Minister for Immigration \& Multicultural \& Indigenous Affairs [2005] FCA 1468 (7 October 2005).

SZFDJ v Minister for Immigration \& Multicultural \& Indigenous Affairs [2005] FMCA 733 (19 May 2005).

SZJSL v Minister for Immigration \& Anor [2007] FMCA 313 (19 February 2007).

Canada

AA0-1226/27 [2001] CRDD No 250 (8 March 2001).

Akhtar v Canada [2004] RPDD No 804 (2 November 2004).

Re BYU [2003] RPDD No 353 (12 May 2003).

Charles v Canada [2003] RPDD No 569 (17 November 2003).

Charles v Canada [2004] FCJ No 2131 (9 December 2004).Dosmakova v Canada [2007] FCJ No 1357 (21 December 2007).

Eringo v Canada [2006] FCJ No 1874 (13 December 2006).

GPC v Canada [2003] RPDD No 444 (13 September 2003).

Hussain v Canada [2004] RPDD No 732 (17 September 2004).

JRN v Canada [2005] FCJ No 1983 (29 November 2005).

Kravchenko v Canada [2004] RPDD No 384 (9 February 2004).

Kravchenko v Canada [2005] FCJ No 479 (16 March 2005).

Khrystych v Canada [2004] RPDD No 339 (15 April 2004).

KRU [2002] RPDD No 165 (1 November 2002).

Laszlo v Canada [2004] RPDD 334 (18 March 2004).

Laszlo v Canada [2005] FCJ No 561 (5 April 2005).

Lekaj v Canada [2006] FCJ No 1151 (14 June 2006).

Leke v Canada [2007] FCJ No 1108 (26 July 2007). 
Mahmood v Canada [2003] RPDD No 636 (18 November 2003).

Magradze v Canada [2006] FCJ No 35 (11 January 2006).

Mora v Canada [2004] FCJ No 1404 (17 July 2004).

Ndagire v Canada [2005] RPDD No 133 (27 December 2005).

Osayamwen v Canada [2004] RPDD No 655 (22 July 2004).

T99-06929 [2000] CanLII 21443 (11 May 2000).

TA5-12778 [2006] CanLii 61444 (26 October 2008).

TA5-13949 [2006] Canlii 61445 (17 May 2006).

Trembliuk v Canada [2003] FCJ No 1590 (30 October 2003).

Yakovenko v Canada [2004] RPDD No 267 (22 January 2004).

Re ZNB [2002] CRDD No 10 (8 March 2002).

New Zealand

Re ED, NZ Refugee Appeal No 1856/93 (25 April 1996).

Refugee Appeal No 71355/99 (14 October 1999).

Refugee Appeal No 73252/02 (24 December 2002).

Refugee Appeal No 75376 (11 September 2006).

United Kingdom

EK (Uganda) v Secretary of State for the Home Department [2004] UKIAT 00021 (12 February 2004).

HJ, Iran [2008] UKAIT 00044 (18 April 2008).

JM v Secretary of State for the Home Department [2008] UKIAT 00065 (11 June 2008).

R v Special Immigration Adjudicator Ex Parte T [2000] EWJ No 3020 (11 May 2000).

References:

AMNESTY INTERNATIONAL UK (2004) Get it Right: How Home Office Decision Making Fails Refugees http://www.amnesty.org.uk/content.asp?CategorylD=838 (accessed 12 August 2008). 
BHUGRA, DINESH (1997) 'Coming Out by South Asian Gay Men in the United Kingdom'. Archives of Sexual Behavior 26(5): 547-557.

BLACKWOOD, EVELYN and WIERNIGA, SASKIA (eds) (1999) Female Desires: Same-Sex relations and Transgender Practices Across Cultures. New York: Columbia University Press.

BLACKWOOD, EVELYN (2000) 'Culture and Women's Sexualities'. Journal of Social Issues 56(2): 223-238.

BÖGNER, DIANA, HERLIHY, JANE and BREWIN, CHRIS (2007) 'Impact of Sexual Violence on Disclosure during Home Office Interviews'. British Journal of Psychiatry 191: 75-81.

BURKE, TIMOTHY (1997) 'Assessing Homosexual Stress'. Journal of Homosexuality 33(2): 83-99.

BYRNE, ROSEMARY (2008) 'Assessing Testimonial Evidence in Asylum Proceedings: Guiding Standards from the International Criminal Tribunals'. International Journal of Refugee Law 19: 609-638.

CASS, VIVIENNE C. (1979) 'Homosexual Identity Formation: A Theoretical Model'. Journal of Homosexuality 4: 219-235.

CASS, VIVIENNE C. (1984) 'Homosexual Identity Formation: Testing a Theoretical Model'. Journal of Sex Research 20: 147-153.

CHUNG, Y BARRY and KATAYAMA, MOTONI (1998) 'Ethnic and Sexual Identity Development of AsianAmerican Lesbian and Gay Adolescents'. Professional School Counseling 1(3): 21-25.

COFFEY, GUY (2003) 'The Credibility of Credibility Evidence at the Refugee Review Tribunal'. International Journal of Refugee Law 15: 377-417.

COX, STEPHEN and GALLOIS, CYNTHIA (1996) 'Gay and Lesbian Identity Development: A Social Identity Perspective'. Journal of Homosexuality 30(4): 1-30.

DAUVERGNE, CATHERINE and MILLBANK, JENNI (2003) 'Before the High Court: Applicants S396/2002 and S395/2002, a Gay Refugee Couple from Bangladesh'. Sydney Law Review 25: 97-124.

DIAMOND, LISA and SAVIN-WILLIAMS, RITCH (2000) 'Explaining Diversity in the Development of SameSex Sexuality Among Young Women'. Journal of Social Issues 25(2): 297-313.

DINDIA, KATHRYN (1998) "'Going Into and Coming Out of the Closet": The Dialectics of Stigma Disclosure', in Montgomery, Barbara and Baxter, Leslie (eds) (1998) Dialectical Approaches to Studying Personal Relationships. New Jersey: Lawrence Erlbaum Associates 83-108.

DUBÉ, ERIC and SAVIN-WILLIAMS, RITCH (1999) 'Sexual Identity Development among Ethnic SexualMinority Male Youths'. Developmental Psychology 35(6): 1389-1398.

EASTMOND, MARITA (2007) 'Stories as Lived Experience: Narratives in Forced Migration Research'. Journal of Refugee Studies 20: 248-264.

FLOWERS, PAUL and BUSTON, KATIE (2001) “I Was Terrified of Being Different": Exploring Gay Men's Accounts of Growing-up in a Heterosexist Society'. Journal of Adolescence 24: 51-65.

GENÇŐZ, TÚLIN and YÜKSEL, MURAT (2006) 'Psychometric Properties of the Turkish Version of the Internalised Homophobia Scale'. Archives of Sexual Behavior 35: 597-602. 
GONSIOREK, JOHN and RUDOLPH, JAMES R. (1991) 'Homosexual Identity: Coming Out and Other Development Events', in Gonsoriek, John and Weinrich, James (eds) (1991) Homosexuality: Research Implications for Public Policy, Newbury Park, CA: Sage.

HALPIN, SEAN and ALLEN, MICHAEL (2004) 'Changes in Psychosocial Well-Being during Stages of Gay Identity Development'. Journal of Homosexuality 47(2): 109-126.

HERLIHY, JANE, SCRAGG, PETER and TURNER, STUART (2002) 'Discrepancies in Autobiographical Memories - Implications for the Assessment of Asylum Seekers: Repeated Interview Studies'. British Medical Journal 324: 324-327.

HERLIHY, JANE, and TURNER, STUART (2007a) 'Memory and Seeking Asylum'. European Journal of Psychotherapy and Counselling 9(3): 267-276.

HERLIHY, JANE, and TURNER, STUART (2007b) 'Asylum Claims and Memory of Trauma: Sharing Our Knowledge'. British Journal of Psychiatry 191(1): 3-4.

HERLIHY, JANE, GLEESON, KATE and TURNER, STUART (2009) 'What Assumptions about Human Behaviour Underlie Asylum Judgments' forthcoming.

HERMAN, DIDI (2005) “I'm Gay": Declarations, Desire, and Coming Out on Prime-Time Television'. Sexualities 8: 7-29.

HOTOWITZ, JANNA and NEWCOMB, MICHAEL (2001) 'A Multidimensional Approach to Homosexual Identity'. Journal of Homosexuality 24(2): 1-19.

IMMIGRATION AND REFUGEE BOARD (1996) Guideline 4, Women Refugee Claimants Fearing GenderRelated Persecution available at http://www.irb.gc.ca/en/about/guidelines/women/womentoc_e.htm

JOHNS, DONNA and PROBST, TAHIRA (2004) 'Sexual Minority Identity Formation in an Adult Population'. Journal of Homosexuality 47(2): 81-90.

KAGAN, MICHAEL (2003) 'Is Truth in the Eye of the Beholder? Objective Credibility Assessment in Refugee Status Determination'. Georgetown Immigration Law Journal 17: 367-415.

KIMMEL, DOUGLAS and YI, HUSO (2004) 'Characteristics of Gay, Lesbian, and Bisexual Asians, Asian Americans, and Immigrants from Asia to the USA'. Journal of Homosexuality 47(2): 143-172.

KNEEBONE, SUSAN (1998) 'The Refugee Review Tribunal and the Assessment of Credibility: An Inquisitorial Role?' Australian Journal of Administrative Law 5: 78-96.

LaVIOLETTE, NICOLE (1997) 'The Immutable Refugee: Sexual Orientation in Canada (AG) v Ward'. University of Toronto Faculty of Law Review 55: 1-41.

LaVIOLETTE, NICOLE (2004) Sexual Orientation and the Refugee Determination Process: Questioning a Claimant about their Membership in the Particular Social Group. Immigration and Refugee Board, Canada, unpublished manuscript on file with authors.

LaVIOLETTE, NICOLE (2007) 'Gender-Related Refugee Claims: Expanding the Scope of the Canadian Guidelines'. International Journal of Refugee Law 19: 169-214. 
LIANG, ANITA C. (1997) 'The Creation of Coherence in Coming-Out Stories', in Livia, Anna and Hall, Kira (1997) Queerly Phrased: Language, Gender and Sexuality, New York: Oxford University Press.

MASON, GAIL (2002) The Spectacle of Violence New York: Routledge.

McGHEE, DEREK (2000) 'Accessing Homosexuality: Truth, Evidence and the Legal Practices for Determining Refugee Status - The Case of Ioan Vraciu'. Body and Society 6: 29-50.

MEYER, ILAN H. (1995) 'Minority Stress and Mental Health in Gay Men'. Journal of Health and Social Behaviour 36: 38-56.

MILLBANK, JENNI (2002) 'Imagining Otherness: Refugee Claims on the Basis of Sexuality in Canada and Australia'. Melbourne University Law Review 26: 144-177.

MILLBANK, JENNI (2004) 'It's About This: Lesbians, Prison, Desire'. Social and Legal Studies 13: 155-190.

MILLBANK, JENNI (2005) 'A Preoccupation with Perversion: The British Response to Refugee Claims on the Basis of Sexual Orientation 1989-2003'. Social and Legal Studies 14: 115-138.

MILLBANK, JENNI (2009a) 'From Discretion to Disbelief: Recent Trends in Refugee Determinations on the Basis of Sexual Orientation in Australia and the United Kingdom'. International Journal of Human Rights 13(2/3): (forthcoming).

MILLBANK, JENNI (2009b) “The Ring of Truth": A Case Study of Credibility Assessment in Particular Social Group Refugee Determinations'. International Journal of Refugee Law 21(1):(forthcoming).

MORRIS, JESSICA (1997) 'Lesbian Coming Out as a Multidimensional Process'. Journal of Homosexuality 33(2): 1-22.

NOLL, GREGOR (2006) 'Asylum Claims and the Translation of Culture into Politics' Texas International Law Journal 41: 491-502.

O'DWYER, PAUL (2008) 'A Well-Founded Fear of Having my Sexual Orientation Asylum Claim Heard in the Wrong Court'. New York Law School Law Review 52: 185-212.

UNHCR (2002) Guidelines on International Protection: Gender-Related Persecution within the Context of Article $1 \mathrm{~A}(2)$ of the 1951 Convention and/or its 1967 Protocol relating to the Status of Refugees. HCR/GIP/02/01.

UNHCR (2008) Guidance Note on Refugee Claims Relating to Sexual Orientation and Gender Identity.

REHAAG, SEAN (2008) 'Patrolling the Borders of Sexual Orientation: Bisexual Refugee Claims in Canada'. McGill Law Journal 51: 59-102.

ROBSON, RUTHANN (1998) Sappho Goes to Law School, New York: Columbia University Press.

ROWEN, CHRISTOPHER and MALCOLM, JAMES (2002) 'Correlates of Internalized Homophobia and Homosexual Identity Formation in a Sample of Gay Men'. Journal of Homosexuality 43(2): 77-92.

TROIDEN, RICHARD R. (1989) 'The Formation of Homosexual Identities'. Journal of Homosexuality 7(1/2): 43-73. 
VANCE, CAROL (1989), 'Social Construction Theory: Problems in the History of Sexuality', in Homosexuality, Which Homosexuality? London: GMP.

WELLS, G. BEVERLY and DOWNING HANSEN, NANCY (2003) 'Lesbian Shame: Its Relationship to Identity Integration and Attachment'. Journal of Homosexuality 45(1): 93-110.

WHITAM, FREDERICK, DASKALOS, CHRISTOPHER, SOBOLWESKI, CURT and PADILLA, PETER (1998) 'The Emergence of Lesbian Sexuality and Identity Cross-Culturally: Brazil, Peru, the Philippines, and the United States'. Archives of Social Behavior 27(1): 31-56.

WONG, CHI-YAN and TANG, CATHERINE SO-KUM (2004) 'Coming Out Experiences and Psychological Distress of Chinese Homosexual Men in Hong Kong'. Archives of Sexual Behavior 33(2): 149-157.

\footnotetext{
Notes

${ }^{1}$ This was recognised by the Federal Court of Canada in a decision overturning an earlier finding by the tribunal that the applicant was not gay because he used the word 'normal' as a synonym for heterosexual (Lekaj v Canada [2006] para 9).

${ }^{2}$ See eg Ndagire v Canada [2005] where the board purported to apply the gender guidelines and yet questioned the claimant about why she 'would allow herself to be sexually assaulted' (para 9, emphasis added). Upheld on judicial review (JRN v Canada [2005]).

3 The judicial review was successful and the matter was remitted but the application was again denied on rehearing (email communication with RRT 24 April 2008).

${ }^{4}$ In Canada, women appeared in $18 \%$ of decisions overall, but comprised $32 \%$ of bisexuality claims, while in Australia women accounted for $16 \%$ of claims overall and appeared in $30 \%$ of decisions on bisexuality.

${ }^{5}$ There were 23 bisexual claims in Australia and 19 in Canada in the entire study, with positive rates of $22 \%$ and $21 \%$ respectively. This compares to an overall rate of positive decisions for sexual orientation claims in our study of $26 \%$ in Australia and $32 \%$ in Canada.
} 